\title{
A Numerical Study of Ceiling Jets Based on " $T$ " Pattern Flames
}

\author{
KOHYU SATOH \\ Fire Research Institute of Japan \\ Mitaka, Tokyo 181, Japan
}

ABSTRACT

This paper describes the numerical analysis of ceiling jets relevant to the "Ir" pattern flame which accelerates the fire growth due to a flame burning upward along a corner, using a three-dimensional field model. It was found in calculations that ceiling jets split into two directions along celling-wall intersections when a heat source is located at a marked distance from a corner. Isotherms, velocity vectors and isobaric contours of the split ceiling jet showed the configulation similar to the "T" pettern in the experiments of Williamson et al. The "T"-shaped flow was investigated using "open" and "closed" type fire rooms. Further, it was found that the distance between the corner and heat source plays an important role in forming the "T" pattem and that the temperatures and pressures at the ceiling comer oscillate regularly.

KFY WORDS : finite difference study, "T" pattern flame, comer fire, fire growth, 3-dimensional calculation, field model, ceiling jet

\section{INTRODUCTION}

A flame located jn a room corner becomes remarkably long, easily licks the ceiling and does more severe damage than a flame along only one wall [1]. The combustion of the ceiling accelerates the fire growth. Emmons[2] mentioned the possibjilty to use 3 -dimensional nonsteady codes to analyse the ceiling jet growth. However, only little has previously been studied by the methods. It is meaningful to understand basic phenomena relevant to the ceiling jet growth using field models. Therefore, the author et al. $[3,4]$ have undertaken numerical investigations of ceiling jets.

The upward flame at the celing corner often splits into two dominant directions, one along either intersection of wall-ceiling, which looks like the letter "T". Therefore, the flame morphology was called the "T" pattern by Williamson et al. $[5,6]$ who studied the comer fame due to a gas burner shown in Fig. 1. It was reported [5] that the "T" pattern above a corner gas burner occurred even in cases of walls made of noncombustible material. Mhis suggests the great role played by fluid dynamics around the ceiling corner where the upward flame touches and turns its direction. It must be noted, however, that circular burn-outs at the ceiling corner were also found in experiments [7]. Neither in experiments nor in calculations, however, have the details of the split flame ("Ti" pattern) and circular 
flame front been fully analysed. Since it is not always serious to omit chemical reactions of fires, the present fluid dynamic calculations to predict the thermal convections of ceiling jets have been employed.

\section{NOMENCLATURE}

$\mathrm{C}_{1}$ : constant $\left(=\mathrm{R}_{0} \mathrm{~T}_{0} / \mathrm{u}_{0}^{2}\right)$

$\mathrm{C}_{\mathrm{p}}$ : specific heat

$\mathrm{C}_{2}:$ constant $\left(=\mathrm{R}_{0} \mathrm{~T}_{\mathrm{O}} /(\mathrm{gH})\right)$

Fr : constant $\left(=u_{0} 2 /(g H)\right)$

H : height of ceiling

$\mathrm{P}$ : pressure

Q : heat release rate

$\mathrm{R}_{0}$ : gas constant

I : temperature

$D^{2}$ : distance between corner and heat source

$g$ : gravitational acceleration

$\mathrm{k}$ : thermal conductivity

Pr: Prandtle number ( $=\mu_{\text {eff }} \mathrm{C}_{\mathrm{p}} / \mathrm{k}_{\mathrm{eff}}$ )

$R_{e}:$ local Reynolds number

$$
\left(=\rho_{0} u_{0} \mathrm{H} / \mu_{\text {eff }}\right)
$$

$u, v, w$ : velocity components $Y$ : height above ploor

$x, y, z$ : Cartesian coordinates $\mu$ : viscosity

$\rho$ : density $\tau$ : viscous stress tensor

(Subscripts)

eff: effective (laminar plus turbulent) o : reference quantity

\section{MATHEMATICAL FORMULATION}

\section{Schematics for numerical calculations}

Fires in two types of rooms were examined : a "closed" fire room which was enclosed by 4 walls with a cejling and floor, and an "open" corner fire room with only two contiguous with a ceiling and floor. Figure 2 shows the schematics of the cubic "open" type fire room and nonunifomly divided celis needed for the finite difference calculations. The number of cells was $24 \times 24 \times 19$ (vertical direction). The smallest cells were employed near the intersections, while the largest cells ( 5 times longer on one side than the smallest) were assigned at the middle height.

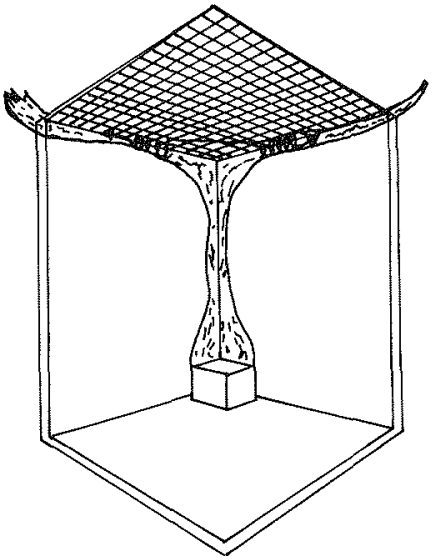

Fig.1 The "T." pattexn flame by Wilitimson et al. [5]

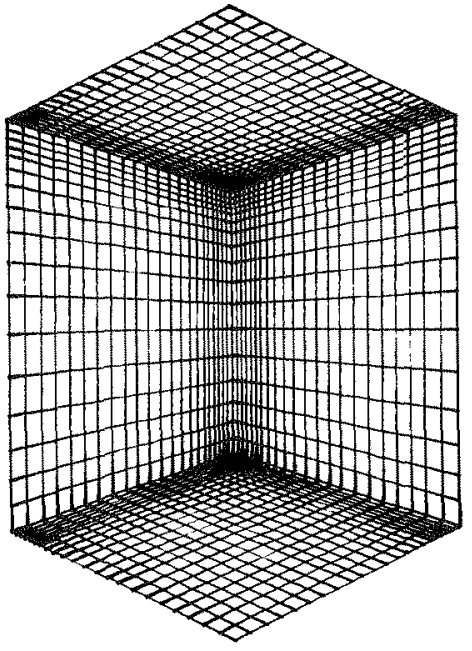

Fig.2 Schematics of divided cells used in the calculations of "open" corner tire. 
The ceiling height of "open" and "closed" cubic fire rooms was either $0.905 \mathrm{~m}$ or $2.438 \mathrm{~m}$. The heating rate varied from 0.5 to $5 \mathrm{~kW}$ for $0.905 \mathrm{~m}$ fire room and 20 to $50 \mathrm{k}$ for $2.438 \mathrm{~m}$ room. Ceiling jets were investigated as a function of the diagonal distance from the corner to the heat source with various dimensions of heat source, but mainly $0.04 \mathrm{~m}$ cubic heat source for $0.905 \mathrm{~m}$ room and $0.15 \mathrm{~m}$ cubic heat source for $2.438 \mathrm{~m}$ room were employed. Although heat source sizes may not agree with the real fire flames, no direct comparisons of numerical results vs. expeximents were aimed here.

\section{Governing differential equations and boundary conditions}

Differential equations used in the present calculations are as follows;

$$
\begin{aligned}
& \frac{\partial(\rho)}{\partial t}+\frac{\partial(\rho u)}{\partial x}+\frac{\partial(\rho v)}{\partial y}+\frac{\partial(\rho w)}{\partial z}=0 \\
& \frac{\partial(\rho u)}{\partial t}+\frac{\partial\left(\rho u^{2}-\tau_{x x}\right)}{\partial x}+\frac{\partial\left(\rho u v-\tau_{x y}\right)}{\partial y}+\frac{\partial\left(\rho u w-\tau_{x z}\right)}{\partial z}=-\frac{\partial P}{\partial x} \\
& \frac{\partial(\rho v)}{\partial t}+\frac{\partial(\rho u v-\tau y x}{\partial x}+\frac{\partial\left(\partial v^{2}-\tau y\right)}{\partial y}+\frac{\partial\left(\rho v w-\tau_{y z}\right)}{\partial z}=-\frac{\partial p}{\partial y}-\left(\rho-\rho_{0}\right) / F r \\
& \frac{\partial(\partial W)}{\partial t}+\frac{\partial\left(\rho U W-\tau_{z X}\right)}{\partial x}+\frac{\partial\left(\rho V W-\tau_{z Y}\right)}{\partial y}+\frac{\partial\left(\rho_{W}{ }^{2}-\tau_{z Z}\right)}{\partial z}=-\frac{\partial P}{\partial z} \\
& \frac{\partial(\rho T)}{\partial t}+\frac{\partial}{\partial x}\left(\rho u T-\left(\frac{I}{\operatorname{Re} \operatorname{Pr}} \frac{\partial T}{\partial x}\right)\right)+\frac{\partial}{\partial y}\left(\rho \mathrm{vT}-\left(\frac{I}{\operatorname{Re} \operatorname{Pr}} \frac{\partial T}{\partial y}\right)\right)+\frac{\partial}{\partial z}\left(\rho w T-\left(\frac{I}{\operatorname{Re} \operatorname{Pr}} \frac{\partial T}{\partial z}\right)\right)=Q \\
& P T=P / C_{1}+P_{0} \\
& \rho_{0}=\exp \left[-Y / C_{2}\right] \\
& \tau_{x x}=\frac{2}{3} u\left(2 \frac{\partial u}{\partial x}-\frac{\partial v}{\partial y}-\frac{\partial w}{\partial z}\right) \\
& \tau_{x y}=\mu\left(\frac{\partial u}{\partial y}+\frac{\partial v}{\partial x}\right)=\tau_{y x} \\
& \tau_{y y}=\frac{2}{3} \mu\left(2 \frac{\partial v}{\partial y}-\frac{\partial w}{\partial z}-\frac{\partial u}{\partial x}\right) \\
& \tau_{z X}=\mu\left(\frac{\partial W}{\partial X}+\frac{\partial u}{\partial z}\right)=\tau_{X z} \\
& \tau_{z z}=\frac{2}{3} \mu\left(2 \frac{\partial w}{\partial z}-\frac{\partial u}{\partial x}-\frac{\partial v}{\partial y}\right) \\
& \tau_{y z}=\mu\left(\frac{\partial v}{\partial z}+\frac{\partial w}{\partial y}\right)=\tau_{z y}
\end{aligned}
$$

Numerical procedures for the present enalysis are based on the methods employed in the computer code UNDSAFE [8, 9] by Yang et al., in which the transfomations of the above equations into a finite difference scheme can be found. The limiting Courant number and Peclet number as a check. were also taken into account, following the original code. However, some modifications were employed in this computer code to accelerate computing speed, extending into the third dimension from the original 2-dimensional UNDSAFE. This 3-D code with about 1000 statements required nearly $1.2 \mathrm{MB}$.

Boundary conditions employed in the calculations were as follows: both the temperatures and velocities at the free boundary are the same as those just at the inside of the boundary, respectively. The velocities on the solid boundaries are zero. All solid boundaries are thermally insulated. A volumetric heat source is employed instead of a gas flame used in the experiments of Wiliamson et al. Chemical reactions of combustion and radiation are neglected in this study. A constant laminar viscosity of air at $20^{\circ} \mathrm{C}$ (i.e., no particular turbulent viscosity model) is employed. 
RESULTS OF NUMERICAL CALCULATIONS

I. Effect of location of heat source and walls

[A] : ["Open" type]
(a) $Y=2.413 \mathrm{~m}$
(b) $y=2.313 \mathrm{~m}$

(1) no gap
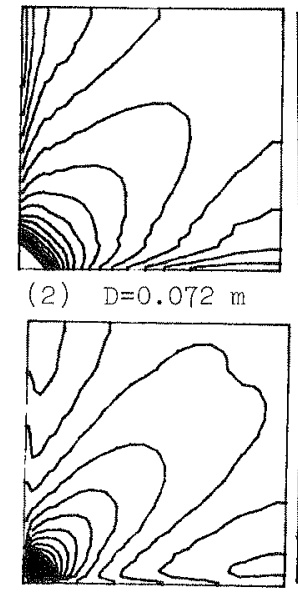

(3) $D=0.180 \mathrm{~m}$

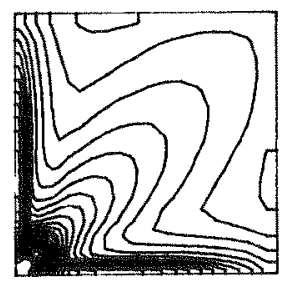

(4) $\mathrm{D}=0.395 \mathrm{~m}$

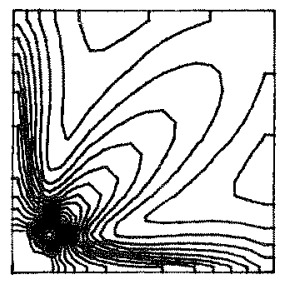

(5) $\mathrm{D}=0.690 \mathrm{~m}$
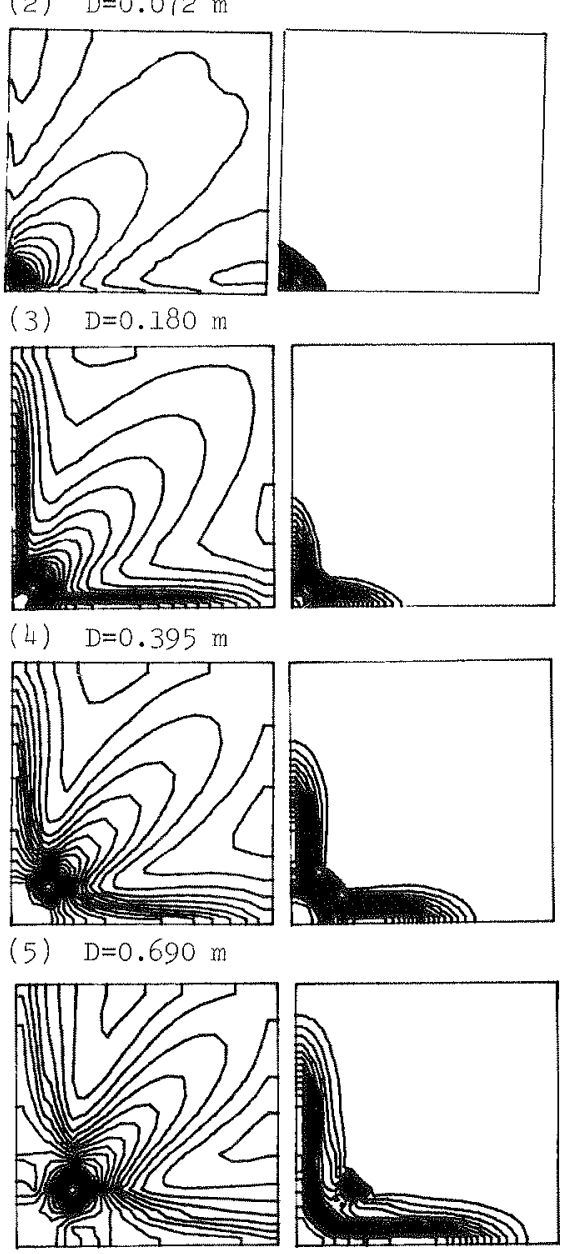
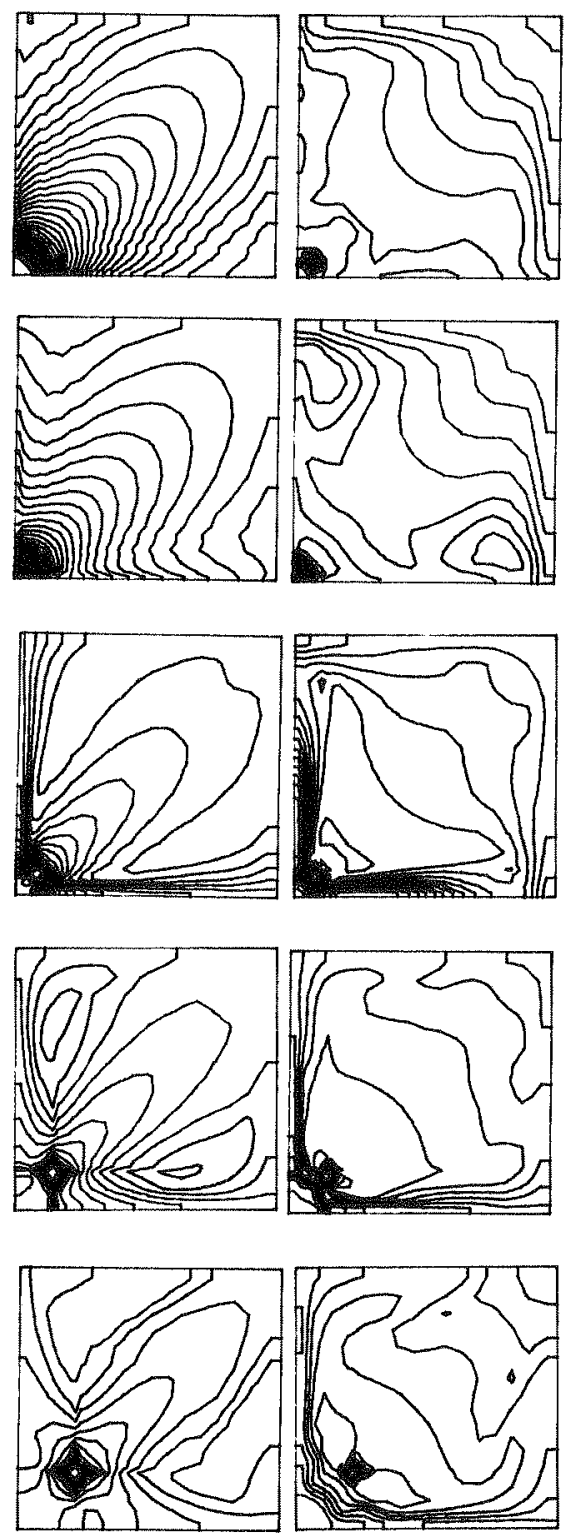

Fig. 3 Isotherms of ceiling jets for "open" and "closed" fire rooms with variations of distance from the heat source. [H=2.438 $\mathrm{m}, \mathrm{Q}=20 \mathrm{~kW}]$ 
Figures 3-(1) to (5) for both "open" and "closed" rooms with the height of $2.438 \mathrm{~m}$ show isotherms in the horizontal two layers beneath the ceiling (the height $Y$ above the floor) with variations of the distance $D$ of the heat source $(Q=20 \mathrm{~kW})$ from the corner. Discrete lines correspond to the temperature difference of $9.3^{\circ} \mathrm{C}$. Temperature aistributions in the ceiling jets are highly affected by the distance between a heat source and walls.

If a heater is located exactly at the corner, concentric circular patterns of isotherms with no split type flow are seen in Figs. 3-[A]-(1) and $[B]-(1)$. If there exists some gap between the heat source and the room corner, ceiling jet flows splitting along both horizontal intersections like the letter " $L "$. The " $L "$-shaped flows in Figs. 3-[A]-(2) and [B]-(2) are, however, less clear. Most typical "L"-shaped flows are observed when a heat source is located at a marked distance, $0.18 \mathrm{~m}$ in Figs. 3-[A]-(3) and $[B]-(3)$, from the corner. Isothemal lines are focused on the ceiling/ wall intersections. The "I" patterns are independent upon the "closed" or "open" rooms, although isotherms at $Y=2.313 \mathrm{~m}$ are different between the two rooms. When the heat source is placed far apart from the corner, the "L"-shaped flow becomes vague.

Further, Fig. 3 shows a flow traversing diagonally, i.e. in the third direction, together with the "L" flow. The diagonal flow temperatures are quite lower than the maximum temperatures in the "L". Williamson et al. reported that the ignition of the remained area is only after the "T" burning. Tsothermal patterns qualitatively gimjlar to those in Fig. 3 , i.e. three dominant flows, were reported in the experiments using a gas burner $[7]$.

\section{Three-dimensional view of isotherms on the ceiling and wall suxfaces}

The 2-dimensional view of the ceiling jet in Fig. 3 indicated the "L"

(A) $Q=2 \mathrm{~kW}$

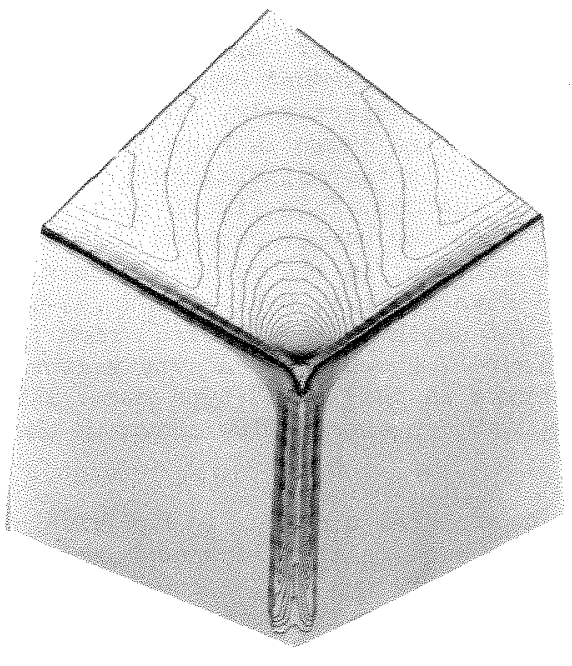

(B) $Q=5 \mathrm{~kW}$

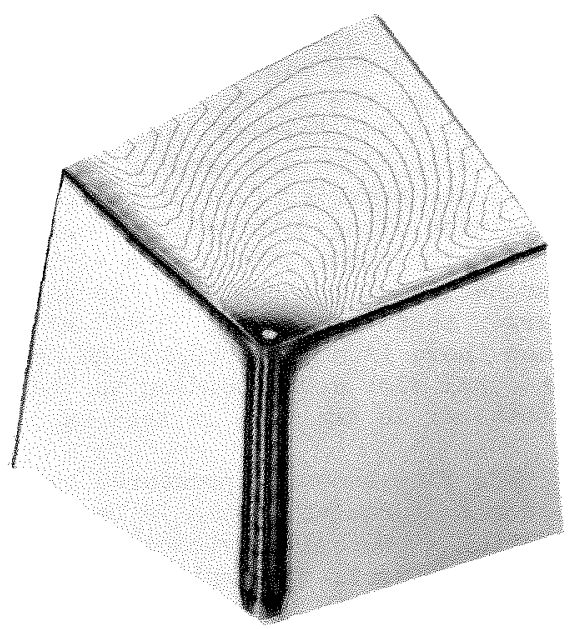

Fig. 4 Three-dimensional view of isotherms on the ceiling and wall surfaces due to a comer heat source. ( $H=0.905 \mathrm{~m}, \mathrm{D}=0.067 \mathrm{~m}$ ) 
configulation. The three-dimensional views of isotherms on the ceiling and walls are shown in Fig. 4, where the heat source $(Q=2$ and $5 \mathrm{kw}$ ) is located at $0.067 \mathrm{~m}$ from the comer for the "open" corner ith $0.905 \mathrm{~m}$ height. The temperature difference between each discrete lines is $8.8^{\circ} \mathrm{C}$. Figure 4 shows the isotherms similar to the "T" pattern. The isotherms are quite dense at the intersections. This indicates that the intersections of the ceiling and wall may first burn at this heat source location, following the impinging region. Figure 5 shows the three-dimensional view of isotherms both exactly at the corner and at the distance slightly far from the corner. Concentric circular isotherms and less clear "T" pattern are seen in Fig. 5 .
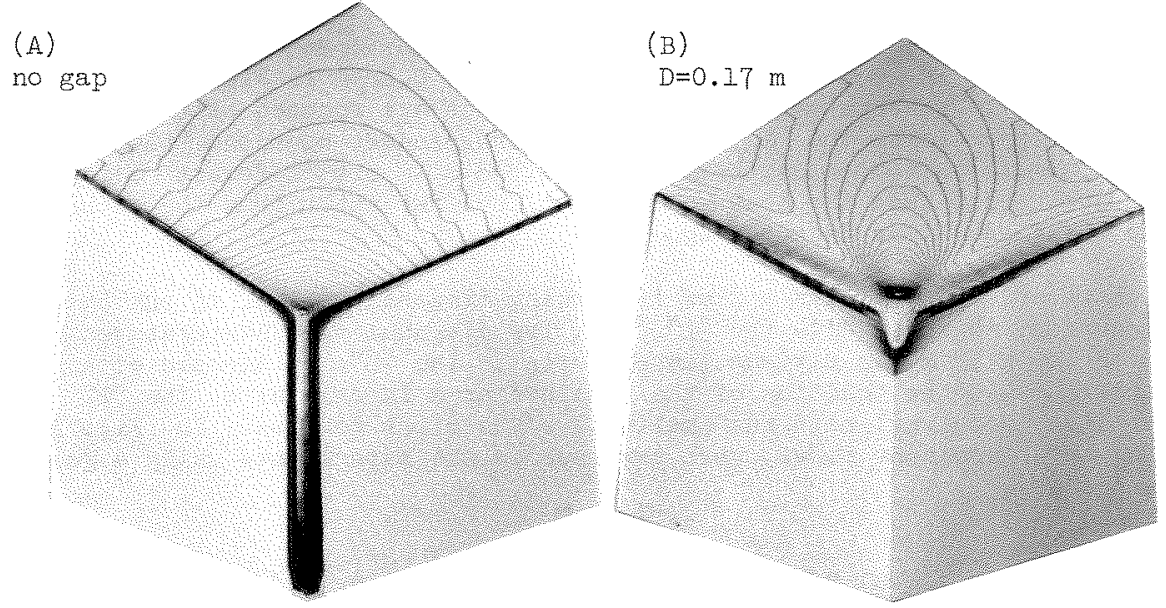

Fig. 5 Isotherms on the ceiling and walls. $(\mathrm{H}=0.905 \mathrm{~m}, \mathrm{Q}=3 \mathrm{~kW})$

\section{Velocity Vectors.}

Figures 6-(A) and (B) show the velocity vectors for "open" and "closed" comers, and symbols 1 and 2 indicate the plan view just beneath the ceiling and the side view near the side wall, respectively. The faster flows along the two horizontal intersections are shown in Figs. 6-1 and 2 for "open" and "closed" rooms show. Like the isotherms, diagonally traversing flows are seen in the velocity vectors. This figure clearly shows the backward flow of the plume towards the comer changes its flow direction along both ceiling/wall intersections. In the ceiling corner, behind the plume, there is a vortex as show in Figs. $6-(A)-2$ and $(B)-2$. Further, Fig. 6 shows that the ceiling jet depth in the "closed" room is larger than that in the "open" room. Figure 7 shows the velocity vectors when there is no gap behind the heat source in the "open" type room. The diagonal flow corresponding to the circular concentric flow shown in the isotherms is dominant in this case.

The flow behavior presented by the present calculations is not always strongly turbulent. This is because the present calculations employed no particular turbulent viscosity model and also is due to the comparatively large unit cell size which is unable to capture small vortices within the grids. Thus, the turbulence such as spiral flame of the "T" pattern is not sufficiently predicted in this study. However, the velocity vectors calculated in this study are reasonable considering the flow in experiments. 
(A) "Open corner type"

(1) (plan view)

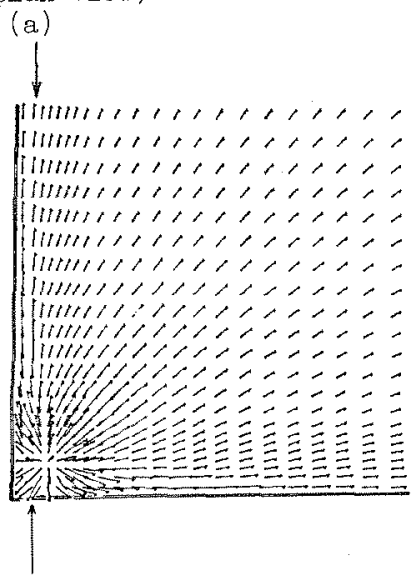

(a)

\section{(2) (side view)}

(b)

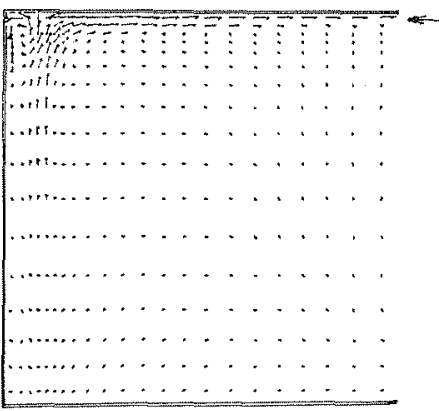

(B) "Closed corner type"

(1) (plan viev)

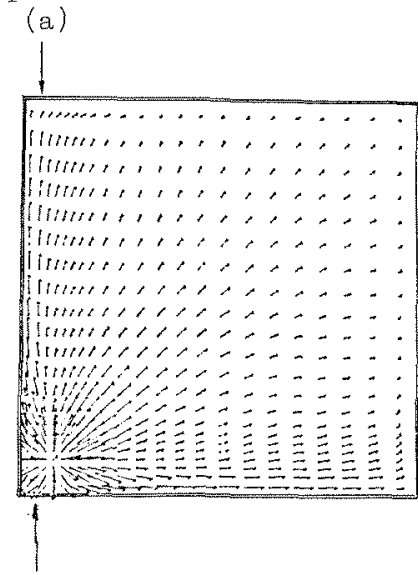

(a)

(2) (side view)

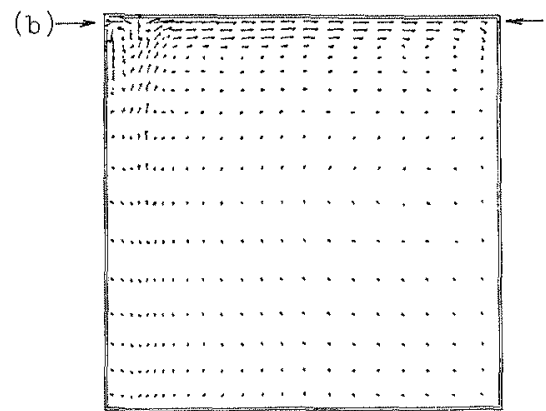

Fig. 6 velocity vectors for "open" and "closed" corners. Arrow (a) shows the position of vertical plane of figure (2) and arrow (b) shows the position of plan view of figure(1). ( $\mathrm{H}=0.905 \mathrm{~m}, \mathrm{Q}=2 \mathrm{~kW}, \mathrm{D}=0.067 \mathrm{~m}$ )
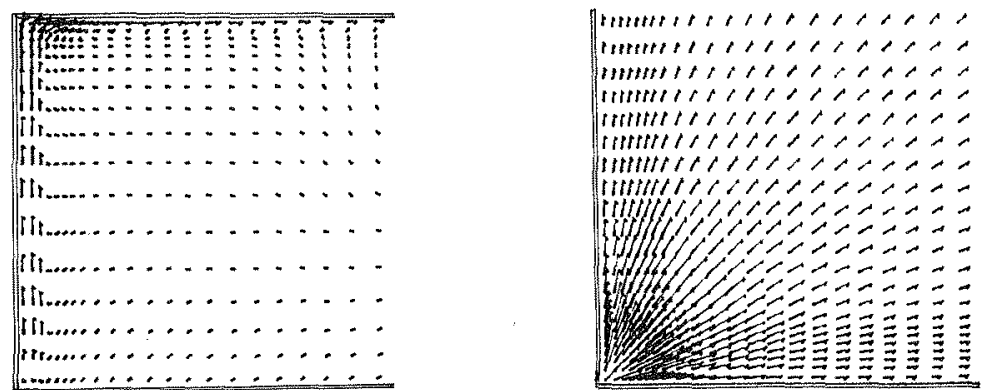

Fig. 7 Velocity vectors for the "open" corner type room with no gap behind the heat source $(\mathrm{H}=0.905 \mathrm{~m}, \mathrm{Q}=2 \mathrm{~kW}, \mathrm{D}=0 \mathrm{~m})$ 


\section{Isobaric contours beneath the ceiling}

Figure 8 shows the plan view of the isobaric contours beneath the ceiling for both the "open" and "closed" corner rooms, corresponding to the case shown in Fig.6. Pressure contours show the "L" pattern, similar to the isotherms.

At the ceiling corner, pressures oscillate regularly, as well as velocities and temperatures.

(A) "Open corner type" (Plan view)

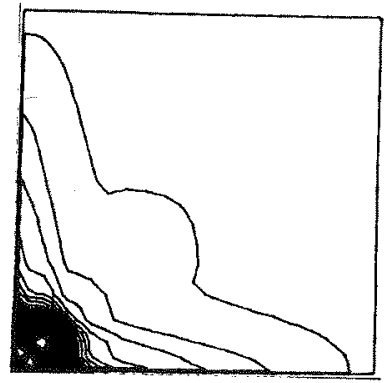

Fig. 8 Isobaric contours for the "open" corner type and "closed" corner type. (Conditions are the same as in Fig. 6)

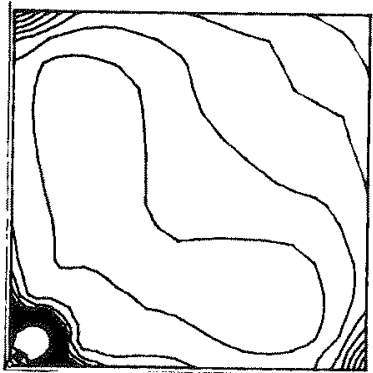

(B) "Closed corner type" (Plan view)

\section{DISCUSSION}

The 3-dimensional "T"- or 2-dimensional "L"-shaped flows calculated in the present study may not always be just the same as the "T" pattern flame in the experiments by Williamson et al., since the calculations took into account the no chemical reactions of gas flame and wall combustion. However, they indicate that the coner flame exposed to noncombustible materials also forms a "T" pattern. This was also reported in anothex experiments [7]. This means that not only are the chemical reaction or combustion phenomena dominant in the "T" pattern flame, but also that fluid dynamic effects are important. The isotherms of the "T" pattern for noncombustible walls should be similar to those of the "p"-shaped flows above a volumetric heat source employed in the present calculations and this study showed the flow patterns ("I"-shaped) similar between the calculations and experiments.

Williamson et al. suggested that "the mechanism for the structure of the "T" pattern flame is that of (1) a vortex structure originally formed on one wall, (2) interrupted by fluctuations in the buoyant plume at the corner, (3) then captured by the flow on the other wall and (4) swept along with the flow at that wall". Other mechanisms suggested are that the vortices are a result of either or both of the following mechanisms: (1) vortex-line-turning at the wall-ceiling junctures due to the spatial variations in the flow field, or (2) the boundary layer flow breakdown away from the junction, and the resulting formation of streamwise vortices. It is, however, not always clear how the upward flame changes its flow into two dominant sideward directions.

There is no doubt that the vortices created around the flame rising along the comer play a great role in the fluctuations at the ceiling 
corner. In particular, if there is some gap between the heat source and the vertical corner, the upward flow along the comer should be turbulent. In the present calculations, too, vortices were found in the ceiling corner and the flow was oscillatory there. However, the turbulence is not strong like in experiments. This mathematical method can predict turbulence and vortices [10]. Thus, turbulent viscosity model, more strong heat source and much smalier unit cell size are recommended.

Numerous vortices and fluctuations will enhance the amount of entrained air into the upward flow. In the experiments of Williamson et al., the gas burner was placed adhering closely to the corner, but the four nozzles of the gas burner had certain gap to the comer according to the photographs of the gas burner. When there is some gap behind the upward flow, the flow partly moves backwards (toward the comer) as seen in the velocity vectors in Fig. 6 . This backward flow partly moves downward along the vertical corner and is again entrained into the upward flow. The remainder of the backward flow splits and moves sideward along the two intersections as seen in Fig. 6. Thus, the buoyant plume together with the some amount of entrained air impinges against the upper ceiling and follows the two ceiling/wall intersections. In the case of no gap behind the upward flow, the buoyant plume is laminar, entrains less air and flows adhering along the corner. Thus, the ceiling jes spreads circulariy as seen in Fig. 5. If the gap behind the upward flow becomes larger, the two sideward flows become vague. Sizable distances enhance the "T" pattern flow.

The entrained air forces the plume into the corner and is pushed back by the increased pressure at the corner, creating regular oscillations of temperatures and pressures. In the case of burning flame, the flame pushed into the corner and entraining air should increase its length. What role will the "T" pattern play in fire growths, e.g. flashover? "The heat of the combustion will be focused more along the ceiling/wall intersections, as well as enhancing both the turbulence and the flame length. This will cause the fire growth from the vertical corner to the ceiling.

\section{CONCLUSTONS}

(1) The present numerical calculations show "T"-shaped isotherms of ceiling jet similex to the "T" pattern flame found in the experiments involving corner combustion by williamson et al. as well as in other experiments, when a heat source is located at a marked distance from the corner. velocity vectors and pressure contours also show the "T"-shaped flow. When there is some gap between the heat source and the corner, not only the temperature but also the pressure behind the plume oscillate. A heat source placed far from the corner shows the vague "T" patterns.

(2) On the formation of the "T" -shaped flows, there is minor difference between the "open" type and "closed" type rooms.

(3) When there is some gap behind the plume, some part of the flow moving backwards (to the corner) changes the direction into the two intersections of the ceiling and wall, i.e. the "T" pattern.

(4) Osillatory flows have a role in increasing the amount of the air entrained into the upward Ilow. The entrained air behind the upward flow plays a role in oscillatory motions.

(5) The "T" pattern plays a role in focusing the heat on the intersections of ceiling/wall and initiating the combustion.

(6) When there is no gap, i.e. In case of a plume adhering closely to the conner, no "T" pattern flow is displayed. In this case, the diagonally traversing flow beneath the ceiling is dominant and spreads circularly. 


\section{ACIKNOWLEDGMENT}

The present study was supported financially by the 1987 Science and Technology Promotion Fund of Science and Technology Agency of Japan.

\section{RETERENCES}

1. Annon., Annual Book of ASTM Standards, Part 18, American Society for Testing and Materials, U.S.A., 1982.

2. Fmmons, H.W., The Needed Fire Science, Proceedings of the First International Symposium on Fire Safety Science, pp.33-53, 1985.

3. Satoh, K. and Evans, D., Comparative Predictions of Fire Generated Cejling Jet Gas Temperatures in an Enclosure using both a Threewayer Zone Model and a Field Model, Proceedings of the Combined Meeting of 1987 Eastern Section Combustion Institute and Annual Meeting on Fire Research, NBS, Washington D.C., No.105-1, 1987 .

4. Satoh, K., Experimental and Finite-Difference Study of Dynamic Fire Behavior in a Cubic Enclosure with a Doorway, Report of Fire Research Institute of Japan, No.55, pp.17-29, 1983.

5. Williamson, R.B., Mowrer, F.W. and Fisher, F.I., Observations of Large Scale Turbulence in Comer-Wall Experiments, Combustion Science and Technology, Vol.41, pp.83-99, 1984.

6. Williamson, R.B. and Baron, F.M., A Corner Fire Test to Simulate Residential Fire, Journal of Fire and Flammability, Vo1.4, pp.99-105, 1973.

7. Satoh, K. and Kozeki, D., A Numerical Study of Buoyant Plume due to a Corner Fire, Proceedings of the lgth Meeting of Fluid Mechenics of Japan (in Japanese), pp.180-183, 1987.

8. Yang, K.T., Lloyd, J.R., Kanury, A.M. and Satoh, K, Modeling of Turbulent Buoyant, Flows in Aircraft Cabins, Combustion Science and Technology, Vol.39, pp.107-118, 1984.

9. Ku, A.C., Doria, M.I. and Lloya, J.R., Numerical Modeling of Unsteady Buoyant Flows Generated by Fire in a Corridor, Proceedings of 16 th (International) Symposium on Combustion, The Combustion Institute, pp.1373-1384, 1976 .

10. Satoh, K., Numerical Calculations of Two-Dimensional Turbulent Free Jet, Proceedings of the 18th Meeting of Fluid Mechanics of Japan, (in Japanese), pp.42-45, 1986 